\title{
SPATIAL DISTRIBUTION AND KNOWLEDGE OF LASSA FEVER EPIDEMIC AMONG PATIENTS PRESENTED FOR TREATMENT IN OWO BETWEEN 2018-2020
}

\author{
Ohemeng-Parker Nana Yaa (MD) and Chukwuyem Abejegah \\ ${ }^{1}$ Department of Public Health and Allied Health, Babcock University, Ilishan-Remo \\ ${ }^{2}$ Consultant Public Health and Community Medicine, Infection Control and Research Centre, \\ Federal Medical Centre, Owo, Ondo State, Nigeria.
}

Cite this article:

Ohemeng-Parker N.Y., Chukwuyem A. (2021), Spatial Distribution and Knowledge of Lassa Fever Epidemic Among Patients Presented for Treatment in Owo Between 2018-2020. African Journal of Environment and Natural Science Research 4(2), 91110. DOI:

10.52589/AJENSR-

ZVU4ODDN.

\section{Manuscript History}

Received: 10 May 2021

Accepted: 6 June 2021

Published: 20 June 2021

Copyright $\odot 2020$ The Author(s). This is an Open Access article distributed under the terms of Creative Commons Attribution-NonCommercialNoDerivatives 4.0 International (CC BY-NC-ND 4.0), which permits anyone to share, use, reproduce and redistribute in any medium, provided the original author and source are credited.
ABSTRACT: Lassa fever outbreaks are known to occur during the dry season (November to April), however, in recent years, cases have also occurred during the rainy season. The study therefore examined the Spatio-temporal pattern and knowledge of Lassa fever epidemics in Owo, Ondo state, Nigeria, 2018-2020. This study adopted a combination of hospital case review and a cross-sectional survey research design. Population for the quantitative aspect was a hospital of 301 individuals addressed for the cluster analyses and 407 treated patients for the questionnaire survey in Owo LGA. A validated questionnaire and data extraction form was used to collect the quantitative data. Cronbach's Alpha reliability test was 0.881. Data was analyzed using Google-Earth Pro, SaTScan and SPSS 27.0 (inferential and descriptive). The result showed that Ehin-Ogbe Street, Aruwajoye street and OkeDogbon street as the highest cluster locations of cases of Lassa Fever in Owo LGA. There is a peak period of Lassa fever cases in the dry season, from November to February. $45.7 \%$ had an average level of knowledge of Lassa Fever. The most statistically significant cluster $(p-0.00048)$ in space and time occurred in April 2019. This was at the peri-urban area proximal to IlaleOsijogun (Idasen) villages and environs. This occurred after an earlier significant outbreak precisely a year earlier in May 2018 at Iyere sub-urban area of Owo city. The largest outbreak subsequently occurred over a 5-month period (August-December 2020). This may be a combination of community transmission, after the two-initial human-animal (zoonotic) transmission phase of 2018-2019. The study recommends primary prevention of rodent-borne diseases can be achieved by avoiding contact with rodents. In improving human behavioural changes, health education strategies should encourage clearing up of bushes, heaps of firewood and rubble around homes as these serve as shelter for rodents. Government should provide adequate supply of PPE for both urban and rural health facilities to assure there are no shortages at the facilities

KEYWORD: Knowledge, Lassa Fever, Spatio-Temporal, Determinants 


\section{INTRODUCTION}

\section{Background}

Lassa fever, also known as Lassa hemorrhagic fever (LHF), is an acute viral haemorrhagic fever caused by the Lassa virus which is a bi-segmented single-stranded RNA virus of the family of Arenaviridae spp (Buchmeier, 2007). It was first discovered in 1969 in a town called Lassa in Borno State, Nigeria (Frame et al., 2017). The primary host of Lassa virus is the natal multimammate rat (many breasted rats called Mastomys natalensis). The primary infection is through contact with the excrete and urine of the rat found in and around homes in most subSaharan African countries, scavenging on food remains or poorly stored food (Werner, 2004). Transmission to man can also be through faecal-oral route, inhalation of contaminated air containing the virus, contact with infected blood, or through sexual intercourse (Ogbu et al., 2017). Lassa fever outbreak has been observed in the West African region like Nigeria, Liberia, Sierra Leone, and Guinea (Monath et al., 2018; Carey et al., 2018).

Statistics about Lassa fever are alarming. According to the World Health Organization (WHO), Lassa fever is endemic in West African countries such as Benin, Ghana, Liberia, Sierra Leone, Guinea, and especially Nigeria (WHO, 2015) where about 300,000-500,000 cases with 5,000 deaths are recorded annually (Bowen et al., 2000) (Ogbu et al., 2007). In Nigeria, Lassa fever is one of the seven epidemic prone notifiable diseases reportable under the Integrated Disease Surveillance System (IDSR), a suspected case is considered an alert threshold and one confirmed case an epidemic threshold.

Lassa fever was first reported in Nigeria in 1969 in Lassa village in Borno state of Nigeria but today has been reported in almost all the 36 states in the country. Fifty-two years after the first report, the disease still continues to account for much of the mortality and morbidity statistics recorded in Nigeria, and particularly in endemic communities with Ondo State and Edo State carrying most of the burden in terms of number of reported cases.

In recent years, between 2018-2020 there were 633 (25\%), 833 (34\%) and 1189 (36\%) cases in Ondo state respectively showing a yearly increase in cases. A total of 5366 suspicious cases were registered from 27 states from 1 January to 19 July 2020, including the Federal Capital Territory (FCT), Abuja. Of these, 1051 positive, 14 probable, and 4315 negatives have been confirmed. There have been 219 deaths among recorded cases since the start of the 2020 outbreak (NCDC, 2020). Nonetheless, these recent figures of suspicious and positive cases are not the actual incidence rate in Nigeria. Lassa fever outbreaks are known to occur during the dry season (November to April), however, in recent years, cases have also occurred during the rainy season (NCDC, 2019). In Nigeria, seasonal Lassa fever outbreaks have persisted, with cases now being reported in states that have not been reported in the past. Ondo, Edo, Bauchi, Nasarawa, Ebonyi, Plateau, Taraba, Abia, Anambra, Adamawa, Gombe, Borno, Kaduna, Kano, Katsina, Benue, Rivers, Kogi, Enugu, Imo, Delta, Oyo, Kebbi, Sokoto, Ogun, Osun and Lagos, these twenty-seven (27) States and FCT have recorded at least one confirmed case across 129 Local Government Areas and Ondo State accounted for the highest of $34 \%$ of the total national figure.

In Ondo State, Lassa fever is now a growing concern for being an endemic disease in most hospitals in the state. It is in the record that Ondo is known as endemic for Lassa fever, with an observed 30\% seropositive prevalence in a countrywide study in 2020 (NCDC, 2020). As a 
communicable disease that has largely become a burden for community members, government, and health care stakeholders.

Lassa fever affects all age-groups and gender with a seasonal clustering around the late rainy season and dry season (WHO, 2020). It is endemic in Ondo state, Edo state, Nasarawa state, and Plateau state with sporadic cases reported in over 22 out of 36 states in Nigeria (NCDC, 2020). Also, outbreak of Lassa fever occurs with recorded fatalities much more than other haemorrhagic fevers including Ebola, but it receives much less attention. Lassa infection is symptomatic in about $20 \%$ of cases when it causes an acute illness with fever and general weakness followed by nonspecific symptoms such as headache, chest pain, vomiting, diarrhea, cough, pleural effusion, bleeding from orifices, and in the late stages, sometimes disorientation and coma. The overall case fatality rate is usually $1 \%$, increasing to $15 \%$ of hospitalized cases.

Lassa fever remains a major challenge to health service providers and has claimed the lives of these great expert resources. For example between 1969 to 2008, the number of documented health workers who died from the disease is as follows: In Jos (1969), a doctor, two nurses and a laboratory staff died; in Onitsha (1972), a doctor and a nurse died; in Ekpoma (1989) two doctors who are brothers died; in Imo (1989) three doctors including a surgeon died; in Lafia (1993, two nurses and two laboratory staff died; in Irrua Specialist Teaching Hospital Irrua (2007) a doctor died; in the Federal Ministry of Health Abuja (2007) a doctor died; in Abakaliki (2008), two doctors and in Benin City (2008) a doctor died. These numbers have increased with more spread within the states in the country between 2009 till date. These skilled medical resources, being wasted by the affliction of Lassa fever is alarming and cuts across all professionals. In the community, the number of affected individuals and deaths recorded has increased immensely since the first reported case.

In Nigeria, a spatial assessment of the Lassa fever outbreak in Bauchi State which occurred in 2015 was unprecedented. It began in mid-November and by January 2016, the virus had already spread to other states like Nasarawa, Niger, Taraba, Kano, Rivers, Edo, Plateau, Gombe and Oyo. A total of 81 cases and 35 deaths were reported, with a mortality rate of $43.2 \%$ (Federal Ministry of Health, 2016). Adequate information and knowledge of the disease is hence imperative and cannot be over-emphasized. A study conducted recently in and around Lafia, North Central Nigeria among 200 respondents revealed that $87 \%$ of the respondents have heard about Lassa fever previously even though there was a misconception on the mode of transmission, while $39 \%$ of the respondents identified bleeding as the major clinical manifestation (Reuben \& Gyar, 2016). In another related study conducted in Odeda Local Government Area of Ogun State, South West Nigeria, result showed that, knowledge of Lassa fever among respondents was fair with (68.3\%) out of the 300 respondents involved in the study have not heard of Lassa fever before, while rural dwellers have the poorest knowledge of the disease (Lawal, 2018). Unfortunately, accurate figures on outbreaks and subsequent responses to arrest the outbreak in Nigeria have not been properly documented (Ajayi, et al., 1995). A number of figures available have only focused on outbreaks that occurred in the past or in recent years, on laboratory diagnosis of suspected cases (Fisher- Hoch et al., 2017; Omilabu et al., 2015; Ehichioya et al., 2020).

The principal reason this study is important at this time is because, there is paucity of literatures focusing on spatial distribution of Lassa fever in Ondo State and information available did not give sufficient information about the determinants of the Lassa Fever cases among residents of Owo area of Ondo State Therefore, the thrust of this is study is to examine the Spatio-temporal 
pattern and knowledge of Lassa fever epidemics among patients presented for treatment in owo between 2018-2020.

\section{Research Questions}

The following research questions that guided this study in the Owo LGA are:

1. What is the spatial distribution pattern of confirmed Lassa fever cases in Owo presented for treatment at the Lassa Fever centre, Federal Medical Center (FMC) Owo, Ondo State, between 2018-2020?

2. What is the level of knowledge of the Lassa fever epidemic in Owo among patients presented for treatment at the FMC Owo, Ondo State between 2018-2020?

\section{Research Hypotheses}

The following research hypotheses was used to guide this research study:

$\mathrm{H}_{1}$ : There is a significant relationship between knowledge of Lassa fever and spatial cluster location of cases among residents of Owo, Ondo State, Nigeria, 2018-2020.

\section{METHODS AND DESIGNS}

\section{Research Design}

This study used a sequential (quantitative) study design. The study design takes cognizance of the type, timeline, and purpose of research as proposed by Babbie (2013). This study adopted a combination of hospital case review and cross-sectional survey research. In this design, the researcher collected and analyzed the quantitative (numeric) data, which was the data collected from the hospital records for the spatio-temporal analysis and the questionnaire survey. The limitations of this design are lengthy time and feasibility of resources to collect and analyze both types of data.

\section{Research Settings}

The study location is Owo in Ondo State, southwestern Nigeria, at the southern edge of the Yoruba Hills (elevation 1,130 feet or $344 \mathrm{~m}$ ). The town is located at the intersection of roads from Akure, Kabba, Benin City, and Siluko. It was created out of the former Ondo province of the former Western state in 1976. It is bounded by the states of Kwara and Kogi on the north, Edo on the east, Delta on the southeast, and Osun and Ogun on the west, and by the Bight of Benin of the Atlantic Ocean on the south. In the era of the city-state, the town between 1400 and $1600 \mathrm{AD}$ was the capital of a Yoruba city-state.

The town is a major collecting point for cocoa, it also serves as a market centre (yams, cassava [Manihot], corn [maize], rice, palm oil and kernels, pumpkins, okra). Cotton and teak are cultivated in the surrounding area, which was originally covered with dense tropical rainforest. Owo has secondary schools, a Federal Polytechnic, St. John's Teacher Training College, a government trade institute, a museum, and several hospitals. The population census of 2006 recorded that the local government area in Ondo State western Nigeria has 222,262 inhabitants 


\section{Population}

This study was targeted at Lassa fever treated individuals of Owo LGA in FMC Owo, Ondo state between 2018-2020 from the whole population of Owo.

Inclusion Criteria: Adults (18 years and above) who were infected with Lassa Fever and treated in FMC Owo.

Exclusion Criteria: Patients who are not up to 18 years who were infected with Lassa Fever and treated in FMC Owo.

\section{Sample Size and Sample Technique}

\section{Sample Size}

The Sequential/Quantitative phase of the study: The first part of this study was the sample size (the sequential/quantitative phase), the spatio-temporal and essentially spatial cluster analyses was inclusive, all data acquired in Owo region from the Lassa fever register at the Federal Medical Center Owo, between the years 2018-2020 was used for the cluster analysis phase of this study. The sample size for the number of Questionnaires to be distributed in this study, was determined using a single formula. The required sample size was calculated by using the Leslie-Kish (1965) formula for estimating sample size.

Sample size was determined using the formula:

$\underline{\mathrm{N}=\mathrm{Z}^{2}} \underline{\underline{P}} \underline{\mathrm{P}(1-\mathrm{P})}$

\section{$\mathrm{D}^{2}$}

\section{Where,}

$\mathrm{N} \quad=$ minimum sample size

$\mathrm{P}=$ the estimated prevalence of value, $36 \%$ cases was reported in Ondo State (National Centre for the Disease Control, (2020)

$\mathrm{D}=$ the absolute precision of the study which is 0.05

$\mathrm{Z}=$ area under normal curve corresponding to $95 \%$ confidence interval.

$\mathrm{Z}=1.96$

Therefore,

$\begin{aligned} \mathrm{N} & =\frac{(1.96)^{2}}{\mathrm{x} 0.36 \times(1-0.36)} \\ \mathrm{N} & =\frac{3.92 \times 0.36 \times 0.64}{0.0025} \\ \mathrm{~N} & =\frac{0.9312}{0.0025} \\ \mathrm{~N} & =373\end{aligned}$


$10 \%$ addition to the attrition rate indicated that $373+37.3=410$ patients with Lassa Fever will be selected for the study. The sample size of 410 respondents was drawn from Owo, Ondo State

\section{Sampling Technique}

The Sequential/Quantitative phase of the study: The questionnaires distributed were based on the cluster locations derived from the spatio-temporal and entirely spatial analyses (the sequential/quantitative) obtained during fieldwork.

\section{Instrumentation for Data Collection}

The quantitative instrument for data collection in this study was a structured Data Extraction Form, a self-developed questionnaire.

\section{The Sequential/Quantitative Phase}

The data extraction form was used to retrieve data from the Lassa fever register in FMC Owo. It included columns for the serial no, date of admission, Gender, and residential address of patients.

The developed questionnaires consisted of 26 questions taking into consideration the objectives of the study. Each section of the questionnaire evaluated the variables and assessed participants' characteristics. The questionnaire was divided into five (5) sections; sociodemographic features, awareness level of Lassa fever, Knowledge on signs and symptoms of Lassa fever

Section 1: This was used to assess the respondents' sociodemographic features which involved their age, level of education, occupation, marital status and religion. It had 6 questions.

Section 2: This was used to assess the respondents' knowledge level of Lassa fever. It had 8 questions with the Yes or No option and the exception of 1 question having multiple choice options making a total of 9 questions.

Section 3: This was used to assess the respondents' Knowledge on signs and symptoms of Lassa fever. It had 1 question with the Yes or No option and the exception of 1 question having multiple choice options making a total of 2 questions.

\section{Validity and Reliability of Instrument}

\section{Validity}

\section{The Sequential/Quantitative Phase}

Validity refers to the degree to which a test measures what it is supposed to measure. In this study, both face and content validity were adopted to authenticate that the study instruments measured exactly what it was designed to measure. The instrument was designed in English was also translated into Yoruba by an expert who was conversant in both languages. This was done in order not to lose the meaning of the items in the questionnaire during the process of translation. 


\section{Reliability}

The reliability of the questionnaire was conducted by administering the instruments to a replica of the proposed study population and its consistency, in yielding the same results to verify its reliability. $10 \%$ of the sample size among the populace was used for the Pre-test.

The result was analyzed using test statistics of Cronbach's Alpha reliability. The overall score gotten from the Cronbach's Alpha reliability test was $\mathbf{0 . 8 8 1}$

\begin{tabular}{|l|l|}
\hline Overall Reliability Statistics \\
\hline Cronbach's Alpha & N of Items \\
\hline .881 & 37 \\
\hline
\end{tabular}

Table 3: Cronbach's Alpha reliability score for each section

\begin{tabular}{|l|l|}
\hline Variable & Value \\
\hline Knowledge on Lassa Fever & 0.826 \\
\hline $\begin{array}{l}\text { Knowledge On Signs And Symptoms Of } \\
\text { Lassa Fever }\end{array}$ & 0.730 \\
\hline
\end{tabular}

\section{Method of Data collection}

\section{The Sequential/Quantitative Phase}

Data needed to plot the geographic / space-time cluster locations were obtained from the Federal Medical Center Owo. This was the hospital of choice because it hosts one of the three Lassa fever treatment centers in Nigeria.

An introductory letter from the Public Health Department was presented to the Federal Medical centre Owo, for approval to collect data from the hospital records. When the approval was granted, a list of all Lassa fever cases from Owo region hospitalized at FMC Owo from 20182020 was obtained from the records department of FMC Owo. The settlements and house addresses were noted.

The houses were traced using the information provided and mapped using google EarthPro. This was used to produce a Lassa fever risk map of Owo.

After the cluster locations were derived from the data retrieved, 407 self-administered questionnaires were distributed to locations with and without spatio-temporal clusters of LF for fair representation of the population based on the sample size estimated by the researcher. This was done by going from door to door and distributing the questionnaires to the residents of the houses. 
Research assistance with an understanding of the area and the dialect spoken was used in order to ensure easy communication with respondents.

\section{Method of Data Analysis}

\section{The Sequential/Quantitative Phase}

Google Earth Pro and SaTScan were used to analyse the data gotten from the hospital register. Google Earth Pro: It is used for the conversion of residential addresses to map points (longitude and latitude) also giving accuracy. It is a 3D interactive globe that is used for analyzing, planning and making decisions.

The following instructions explains how it is done:

- $\quad$ Open Google Earth.

- At the top of the left side of the software, the residential address is inputted into the search bar.

- The map directs you to the exact location on the map

- $\quad$ Select add place-mark

- A small dialogue box is seen, the Longitude and latitude appears there.

- The place-mark can be moved to the exact location you want

SaTScan Software: SaTScan is a software that analyzes spatial, temporal and space-time data.

It is used for the calculation and analyses of the Spatiotemporal and entirely spatial cluster.

The result (cluster location) of the analyses developed from the SaTScan software was entered into an ArcGIS software which produced the pictorial representation of the cluster pattern on the map.

The completed questionnaire's data was analysed using Statistical Social Science (SPSS) version 27.0 software. Both descriptive and inferential statistics were recorded when the data entered and analysed into SPSS. The results were presented using distribution tables.

\section{Ethical Consideration}

The study pursued its ethical approval from the ethical committee of the university - Babcock University Health Research and Ethics Committee (BUHREC). Also, a letter of introduction from the Public Health department was presented to the Federal Medical Centre, Owo and a letter of approval was submitted to the Chairman, Ethical Committee of the Federal Medical Centre, Owo where patient's data were gathered from the hospital register.

During the administration of the questionnaires, the purpose of the study, along with the criteria of participation was clearly explained. It was also stated that there was no risk involved in the study. 


\section{Informed Consent}

In line with the standard ethical procedures for conducting a search, this study sought the consent of the participants before participation in the study. The participants were wellinformed about the objectives of the study with importance of their participation in the study by convincing them. They were given the right to choose, to either participate or decline in participation from the researcher.

\section{Confidentiality}

The study was conducted ensuring participants about confidentiality of information provided by researchers. The researcher did all possible to avoid revealing and protecting the information given by participants from third parties.

\section{Anonymity}

The questionnaires were administered to participants without requiring the names of the respondents. This makes it almost impossible for the researcher and any interested persons to match the participants information to the exact participant who filled the questionnaire.

\section{Right to withdraw}

The researcher informed the respondents that he or she could decide to leave the study at any point in time. It was not binding that a participant who began the study must complete it. The choice to complete the study was entirely the prerogative of the participants.

\section{Dissemination of Result}

Copies of this thesis will be submitted to the Public Health department at Babcock University. The result will be made available to the Ministry of Health in Ondo state. The study will be published in accredited journals, making it available to other researchers as reference points.

\section{Measurement of Variables}

The measurements of variables under investigation were section into 1-7 and their corresponding rating scale are as follows:

\section{RESULT}

This chapter presents results of various descriptive and inferential analyses carried out on data collected in accomplishing the earlier stated objectives and hypotheses. The results are presented in two phases; the spatio-temporal from the SaTScan and the results from the quantitative data (questionnaire). The spatio-temporal clustering included the 3 sets of cluster locations, one primary and two secondaries from the cluster analyses carried out with the pictorial representation of these sets of cluster location on a map. Description of the sociodemographic characteristics, the level of knowledge of Lassa fever. A total of 410 questionnaires were administered to participants in their respective households in Owo through home-tracing. Only 407 participants consented and participated in the study. In general, respondents' participation in terms of giving responses to various questions to the interviewers were highly acceptable and encouraging at the time of carrying out this study. 


\section{Spatio-temporal and Entirely Spatial pattern (cluster pattern) of Owo residents treated Lassa fever persons from FMC Owo, Ondo state between the years 2018-2020. 4.1.1 Spatio temporal cluster location of Owo resident treated Lassa fever persons from FMC Owo, Ondo state between the years 2018-2020.}

After the data gotten from the Lassa fever register this was derived and analyzed using the Space-time permutation model in the SaTScan software, out of the cluster locations derived for Lassa fever from 2018-2020, there was one primary cluster and two secondary cluster locations were statistically significant where $p=0.1$. The statistically significant locations derived are stated below:

\section{Primary Cluster}

1. Location IDs included.: 201, 202, 203, 204, 205, 206, 207, 208

Coordinates / radius..: $(7.169510 \mathrm{~N}, 5.589320 \mathrm{E}) / 0 \mathrm{~km}$

Time frame .$: 2019 / 4 / 1$ to $2019 / 4 / 30$

Number of cases.......: 6

Expected cases $: 0.24$

Observed / expected...: 25.00

Test statistic : 13.608953

P-value. 0.000048

This result indicates that there was a cluster of 6 cases between $1^{\text {st }}-30^{\text {th }}$ April 2019 at coordinate $7.169510 \mathrm{~N}, 5.589320 \mathrm{E}$ within a $0 \mathrm{~km}$ radius, these coordinates when placed on the map is located on a residential area called Idasen in Owo, this goes to show that a lot of people in that particular area were treated for Lassa fever.

\section{Secondary clusters}

2. Location IDs included.: 109, 110, 111

Coordinates / radius..: $(7.178040 \mathrm{~N}, 5.611810 \mathrm{E}) / 0 \mathrm{~km}$

Time frame. $\therefore 2018 / 5 / 1$ to $2018 / 5 / 31$

Number of cases.......: 3

Expected cases 0.060

Observed / expected...: 50.00

Test statistic : 8.810525

P-value. 0.032 
This result indicates that there was a cluster of 3 cases between $1^{\text {st }}-31^{\text {st }}$ May 2018 at coordinate $7.178040 \mathrm{~N}, 5.611810 \mathrm{E}$ coordinate within a $0 \mathrm{~km}$ radius, these coordinates when placed on the map is located on a residential area called Iyere in Owo, this goes to show that a lot of people in that particular area were treated for Lassa fever.

3.Location IDs included.: 2, 24, 10, 21, 29, 14, 28, 18, 9, 27,

$13,20,54,16,75,15$

Coordinates / radius..: $(7.202900 \mathrm{~N}, 5.587750 \mathrm{E}) / 0.35 \mathrm{~km}$

Time frame. : $2020 / 8 / 1$ to $2020 / 12 / 31$

Number of cases .: 8

Expected cases $: 1.17$

Observed / expected...: 6.82

Test statistic. : 8.608654

P-value. .$: 0.041$

This result indicates that there was a cluster of 8 cases between $1^{\text {st }}$ August $-31^{\text {st }}$ December at coordinate $7.202900 \mathrm{~N}, 5.587750 \mathrm{E}$ within a $0.35 \mathrm{~km}$ radius, these coordinates when placed on the map is located on a residential area called Oke-dogbon road in Owo, this goes to show that a lot of people in that particular area were treated for Lassa fever.

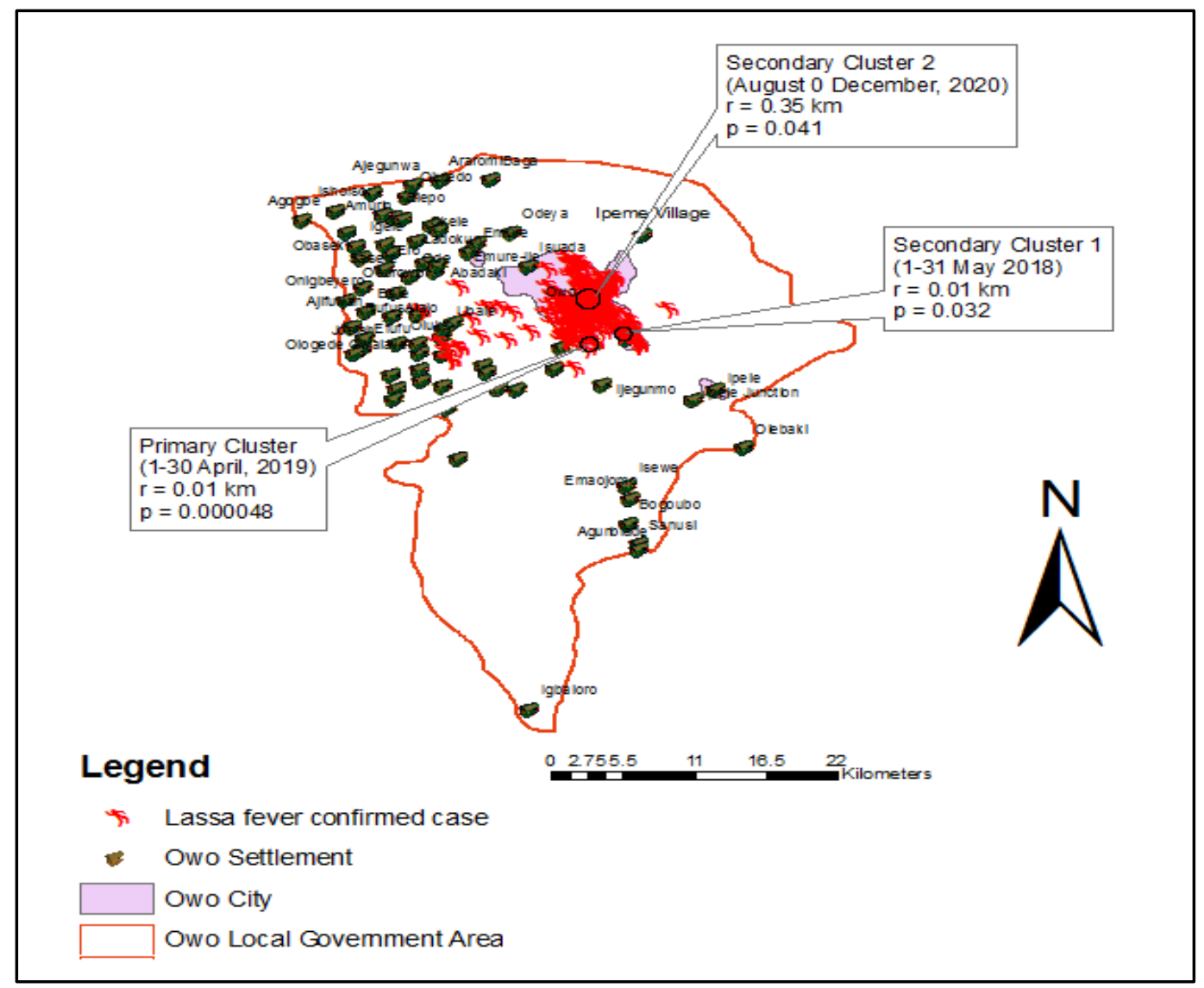

Figure 1: Map of the study location showing the spatio-temporal and entirely spatial clusters of Lassa fever on Owo, Ondo state, 2018-2020 
Figure 4: The principal (primary cluster) and two other non-overlapping clusters of human cases of Lassa fever in Owo Local Government Area, Ondo State, 2018 - 2020. The most statistically significant cluster $(\mathrm{p}-0.00048)$ in space and time occurred in April 2019. This was at the peri-urban area proximal to Ilale-Osijogun (Idasen) and environs. This occurred after an earlier significant outbreak precisely a year earlier in May 2018 at Iyere sub-urban area of Owo city. The occupational engagements at these locations as revealed through the questionnaire survey provided the clue to the risk factors of Lassa fever outbreak in Owo City and the environs during 2018-2020. The largest outbreak subsequently occurred over a 5-month period (August-December 2020). This may be a combination of community transmission, after the two-initial human-animal (zoonotic) transmission phase of 2018-2019. The map of the cluster in space and time identifies association of LF cases with local micro-environment and the type of occupational or cultural activities predisposing to outbreaks.

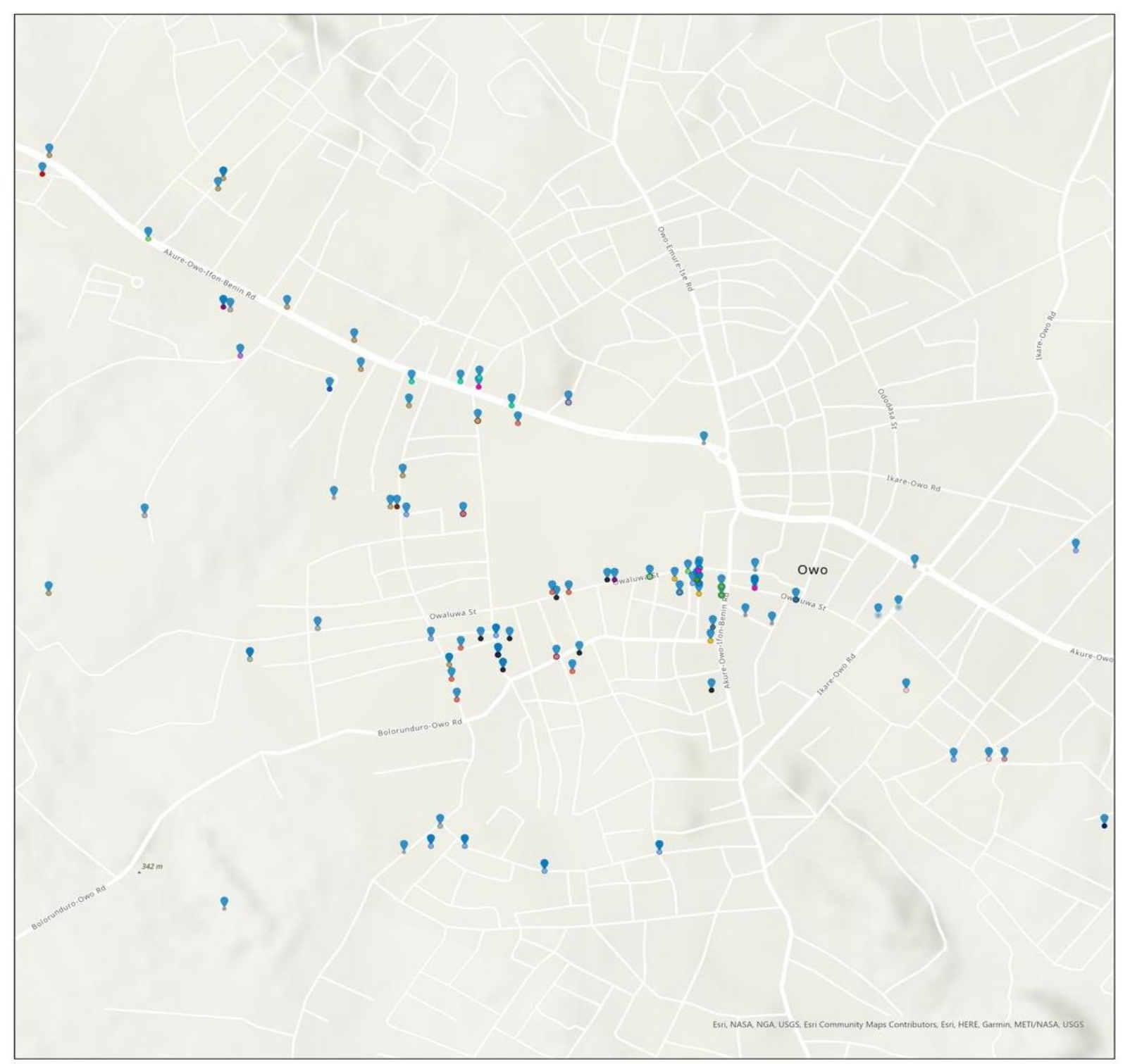

Figure 4.1: Map showing the point location 
African Journal of Environment and Natural Science Research

ISSN: 2689-9434

Volume 4, Issue 2, 2021 (pp. 91-110)

www.abjournals.org

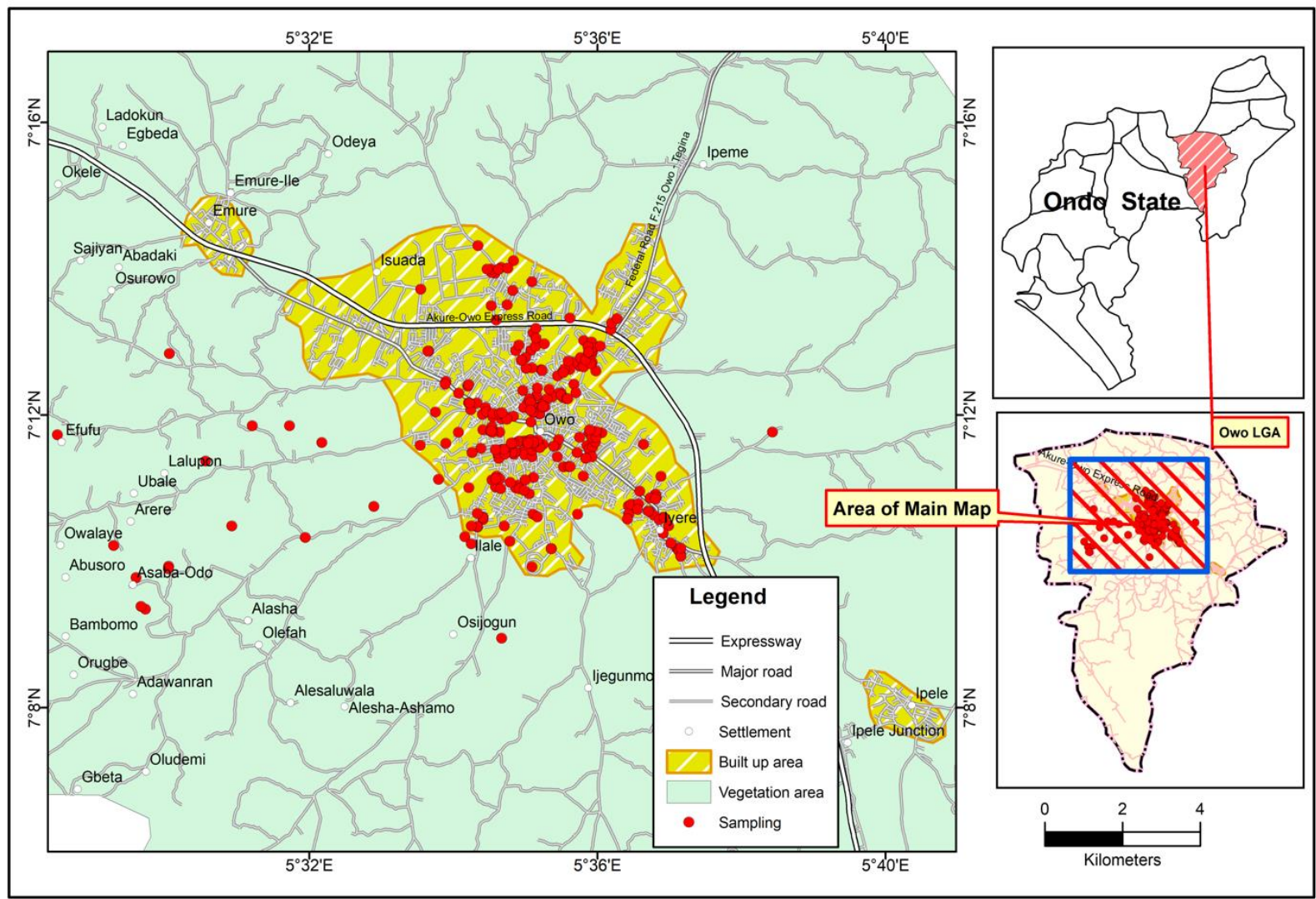

Figure 2: Owo Local Government Area showing sampling point

\section{The Survey Result}

Table 4.: Showing the monthly frequency of Lassa Fever in Time Series, 2018-2020

Location (All)

Count of Location Month

Year January February March April May June July August September October November December GrandTotal

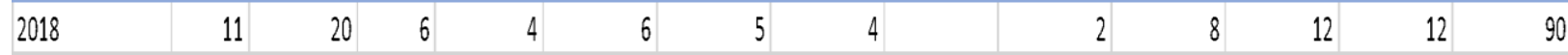

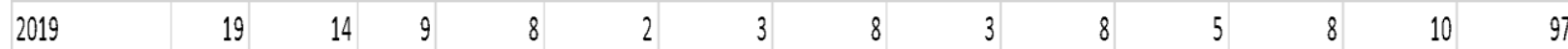

\begin{tabular}{|c|c|c|c|c|c|c|c|c|c|c|c|c|}
\hline 2020 & 41 & 24 & 21 & 3 & 5 & 3 & 2 & 3 & 2 & 4 & 3 & 3 \\
\hline Grand Total & 71 & 58 & 36 & 15 & 13 & 11 & 14 & 6 & 12 & 17 & 23 & 25 \\
\hline
\end{tabular}

From the table, there is a peak period of Lassa fever cases from November to February

There were more cases in March 2020 and reduced cases between November to December 2020 when compared to other years. 


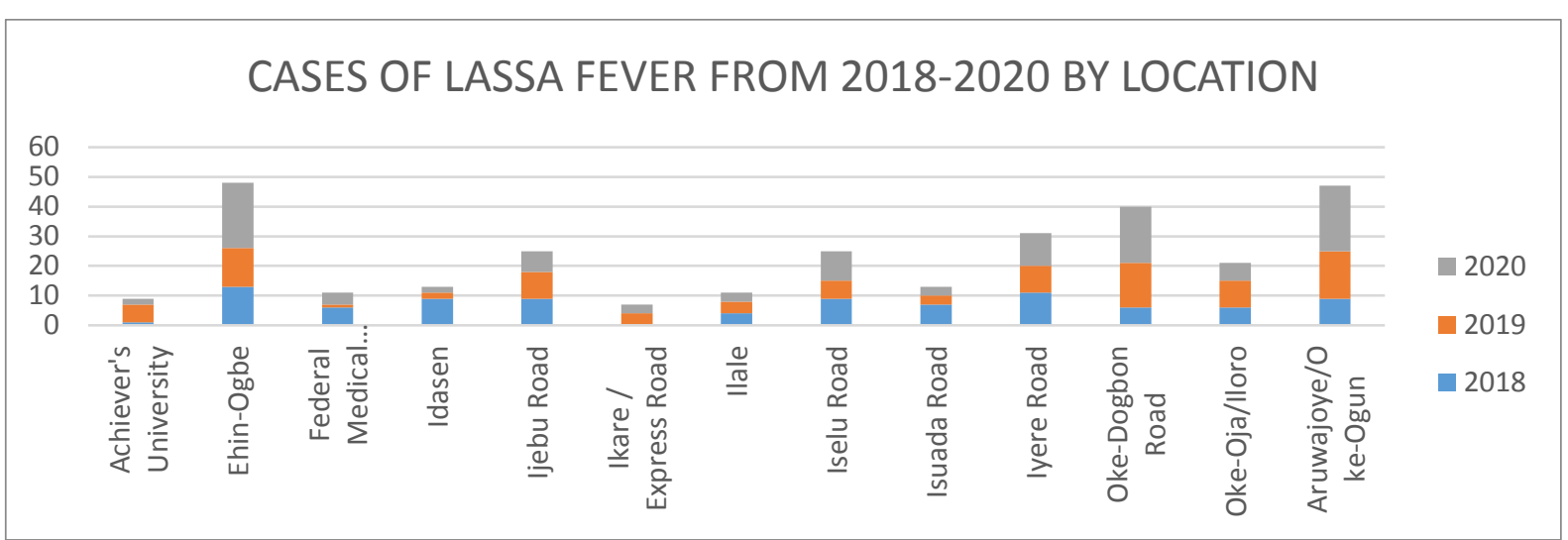

Figure 4.4: Bar chart showing the distribution of Lassa Fever According to location between 2018-2020.

\section{Showing geographic location of epidemics}

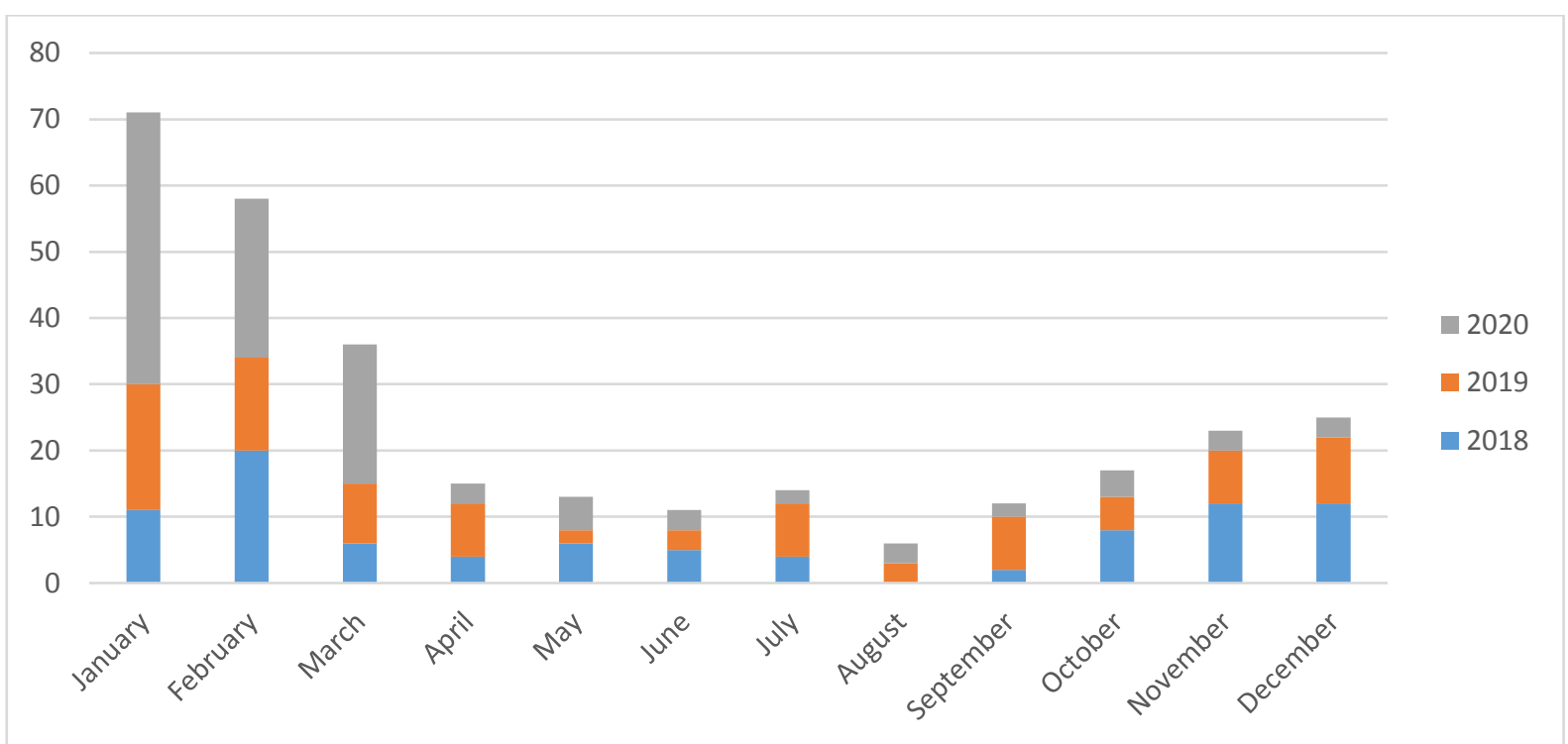

Figure 4.5: Bar chart showing the distribution of Lassa Fever According to months between 2018-2020.

\section{Socio-demographic Characteristics of Respondents}

Below indicated that $60.2 \%$ are above the age of 41 years, $30 \%$ are between the ages of 36 40years. $57.2 \%$ are male while $42.8 \%$ of the patients are female. Over half of the patients only had primary school education, $21.5 \%$ had secondary school education. $43.7 \%$ of the patients are farmers, $17.4 \%$ are health workers while $17.2 \%$ are business owners while $14.3 \%$ students and $7.4 \%$ are civil servants. $71.5 \%$ are married while $28.5 \%$ are single. $54.3 \%$ of the respondents are Christian by faith while $42.5 \%$ are Muslim and 3.2\% practice the traditional religion. 
Table 1: Analysis of Characteristics of the patients Demographic among participants in this study $\mathbf{N}=\mathbf{4 0 7}$

\begin{tabular}{lcc}
\hline Demographic Characteristics & Frequency & Percentage \\
\hline Age & 8 & \\
26-30years & 32 & 2.0 \\
31-35years & 122 & 7.9 \\
36-40years & 245 & 30.0 \\
above 41 years & & 60.2 \\
Mean Age: 55.2, S.D=12.7 & 233 & \\
Sex & 174 & 57.2 \\
Male & & 42.8 \\
Female & 43 & 10.6 \\
Level of Education & 233 & 57.2 \\
No formal education & 88 & 21.6 \\
Primary education & 43 & 10.6 \\
Secondary education & & \\
Tertiary education & 30 & 7.4 \\
Occupation & 178 & 43.7 \\
Farmer & 71 & 17.4 \\
Civil servant & 70 & 17.2 \\
Health Worker & 58 & 14.3 \\
Business & & \\
Student & 116 & 28.5 \\
Marital Status & 291 & 71.5 \\
Single & & \\
Married & & 54.3 \\
Religion & 221 & 42.5 \\
Christian & 173 & 3.2 \\
Islam & 13 & \\
Traditional & & \\
\hline & & \\
\end{tabular}

\section{Level of knowledge of Lassa Fever.}

Below reported that $53.6 \%$ have heard of Lassa fever. $22.1 \%$ reported to know about Lassa fever through a friend, $13.8 \%$ reported school, $13.8 \%$ of the participants could not remember while $14.3 \%$ reported got to know about Lassa fever from their place of worship while 3.7\% reported other sources. 56.3\% are aware of the causative agent of Lassa Fever. 14.7\% reported Bacteria while $10.6 \%$ do not know and 3.4\% reported other causative agents of Lassa fever. $53.3 \%$ of the respondents have heard of the animal species which transmit the disease agent of Lassa fever. Over half of the participants reported Rats, $25.1 \%$ reported Squirrel while $17.4 \%$ reported Rabbits. $67.8 \%$ are aware that Lassa fever can transmit from one person to another while $56.8 \%$ reported that it can be spread through sexual intercourse. 
African Journal of Environment and Natural Science Research

ISSN: 2689-9434

Volume 4, Issue 2, 2021 (pp. 91-110)

www.abjournals.org

Table 2: Analysis of Knowledge of Lassa Fever $\quad$ N= 407

\begin{tabular}{|c|c|c|c|}
\hline Knowledge of Lassa Fever Question & Categories & Frequency & Percentage \\
\hline \multirow[t]{2}{*}{ Have you ever heard of Lassa fever } & Yes & 218 & 53.6 \\
\hline & No & 189 & 46.4 \\
\hline \multirow[t]{8}{*}{ Source(s) of awareness } & Mass media & 44 & 10.8 \\
\hline & Friends & 90 & 22.1 \\
\hline & Hospital & 45 & 11.1 \\
\hline & School & 56 & 13.8 \\
\hline & Text books & 43 & 10.6 \\
\hline & Can't remember & 56 & 13.8 \\
\hline & Worship centre & 58 & 14.3 \\
\hline & Others & 15 & 3.7 \\
\hline Are you aware of the causative agent of & Yes & 229 & 56.3 \\
\hline Lassa fever? & No & 178 & 43.7 \\
\hline \multirow[t]{5}{*}{ What is the causative agent of Lassa fever? } & Bacteria & 60 & 14.7 \\
\hline & Virus & 145 & 35.6 \\
\hline & Animal & 145 & 35.6 \\
\hline & I don't know & 43 & 10.6 \\
\hline & Others & 14 & 3.4 \\
\hline \multirow{2}{*}{$\begin{array}{l}\text { Have you ever heard of the animal species } \\
\text { that transmit the disease agent? }\end{array}$} & Yes & 217 & 53.3 \\
\hline & No & 190 & 46.7 \\
\hline \multirow{3}{*}{$\begin{array}{l}\text { Which of these animals transmit the } \\
\text { causative agent? }\end{array}$} & Rabbits & 71 & 17.4 \\
\hline & Rats & 234 & 57.5 \\
\hline & Squirrel & 102 & 25.1 \\
\hline \multirow{4}{*}{$\begin{array}{l}\text { Can Lassa fever be transmitted from one } \\
\text { person to another? } \\
\text { Can Lassa fever be spread through sexual } \\
\text { intercourse? }\end{array}$} & Yes & 276 & 67.8 \\
\hline & No & 131 & 32.2 \\
\hline & Yes & 231 & 56.8 \\
\hline & No & 176 & 43.2 \\
\hline
\end{tabular}

\section{Answering of research questions One on the level of Knowledge of Lassa Fever}

This study asked 13 questions relating to the level of knowledge about Lassa Fever among residents' patients of Owo. Maximum score obtainable is 26. Their level of knowledge was categorized as Good (19-25), Fair (10-18) and low (1-9). 41\% had a fair level of knowledge about Lassa Fever while $32.7 \%$ had good awareness and $26.3 \%$ had a poor level of awareness.

Table 2b: Summary of level of knowledge of Lassa Fever N=407

\begin{tabular}{ccc}
\hline Criteria & Frequency & Percentage \\
\hline Good (19-26) & 133 & 32.7 \\
Fair (10-18) & 167 & 41 \\
Low (1-9) & 107 & 26.3 \\
& Mean $=\mathbf{1 7 . 8 ,}$ Std. Dev $=\mathbf{3 . 2 6}$ & \\
\hline
\end{tabular}




\section{Knowledge of Signs and Symptoms of Lassa Fever}

Below indicated, $67.3 \%$ are aware of the signs and symptoms of Lassa Fever. $54.5 \%$ of the respondents reported bleeding manifestation, one of the signs of Lassa fever. $68.1 \%$ reported high body temperature. 60.4\% reported Nausea and vomiting while $78.9 \%$ reported Diarrhoea. $75.2 \%$ reported sweating. $71.5 \%$ reported body weakness while $67.5 \%$ did not report spontaneous abortion in pregnancy for women.

Table 3 Analysis of Knowledge of Signs and Symptoms of Lassa Fever N=407

\begin{tabular}{|l|l|l|}
\hline Knowledge of Signs and Symptoms of Lassa Fever Yes & Yes & No \\
\hline Have you ever heard of any signs and symptoms of Lassa fever? & $274(67.3 \%)$ & $133(32.7 \%)$ \\
\hline Bleeding manifestation & $222(54.5 \%)$ & $185(45.5 \%)$ \\
\hline High body temperature & $277(68.1 \%)$ & $130(31.9 \%)$ \\
\hline Nausea and vomiting & $246(60.4 \%)$ & $161(39.6 \%)$ \\
\hline Diarrhoea & $321(78.9 \%)$ & $86(21.1 \%)$ \\
\hline Sweating & $306(75.2 \%)$ & $101(24.8 \%)$ \\
\hline Body weakness & $291(71.5 \%)$ & $116(28.5 \%)$ \\
\hline Spontaneous abortion in pregnant women & $132(32.4 \%)$ & $275(67.5 \%)$ \\
\hline
\end{tabular}

\section{Answering of research questions two on the level of Knowledge of Signs of Lassa Fever}

This study asked 8 questions relating to the level of knowledge about Lassa Fever among residents' patients of Owo. Maximum score obtainable is 16 . Their level of knowledge of Lassa Fever categorized as Good (11-16), Fair (6-10) and low (1-5). 45.7\% had an average level of knowledge of Lassa Fever, 30\% had a good knowledge while $24.3 \%$ had a poor level of knowledge of Lassa Fever.

Table 3b: Summary of level of Knowledge of Signs of Lassa Fever N=407

\begin{tabular}{ccc}
\hline Criteria & Frequency & Percentage \\
\hline Good (11-16) & 122 & 30 \\
Average (6-10) & 186 & 45.7 \\
Poor (1-5) & 99 & 24.3 \\
& Mean $=\mathbf{1 0 . 5}$; Std. Dev $=\mathbf{1 . 3 2}$ & \\
\hline
\end{tabular}

\section{DISCUSSION OF FINDINGS}

\section{Knowledge about Lassa Fever}

The result of research question one showed that for most of the patients $41 \%$ had a fair level of knowledge about Lassa Fever while $32.7 \%$ had good awareness and $26.3 \%$ had poor level of awareness. This implies that the majority of the participants are very much inclined with Lassa fever especially when presented in the hospital with the diagnosis that is similar to what they have. The result is consistent with WHO (2016) that most patients in developing regions of 
the world with symptoms of Lassa fever often present in rural health centres, with minimal knowledge of the virus. The result is in tandem with the findings of Amorosa, MacNeil, McConnell, Patel, Dillon, Hamilton, Erickson, Campbell, Knust, Cannon, Miller, Manning, Rollin, and Nichol (2018) that generally, residents of rural communities during the medical outreach reported to have average level of awareness of about Lassa fever in the republic of congo where there is paucity of resources. The result is in support of the fact that Lassa fever outbreaks are known to occur during the dry season (November to April), however, in recent years, cases have also occurred during the rainy season (Ilori, 2018) especially among residents of low- and middle-income countries where resources are limited. The result implies that there is a need for more public health education on different strategies of preventing Lassa Fever among residents across different spectrum of care.

\section{Spatial distribution pattern of confirmed Lassa fever}

The result on the spatial distribution of confirmed cases of Lassa Fever indicated that the most statistically significant cluster $(p-0.00048)$ in space and time occurred in April 2019. This was at the peri-urban area proximal to Ilale-Osijogun (Idasen) and environs. This occurred after an earlier significant outbreak precisely a year earlier in May 2018 at Iyere sub-urban area of Owo city. The occupational engagements at these locations as revealed through the questionnaire survey provided the clue to the risk factors of Lassa fever outbreak in Owo City and the environs during 2018-2020. The map of the cluster in space and time identifies association of LF cases with local micro-environment and the type of occupational or cultural activities predisposing to outbreaks. The result is consistent with the findings of Yunusa \& Egenti (2015) that duration of time and space were significantly associated with the increasing prevalence of confirmed cases of Lassa Fever in developing countries of the world. Similar to this report is that of Saliu, et al, 2020) that there is practically a spatial distribution of the pattern of lassa fever, hence the association of housing location and distribution could not ascertain in most regions in Nigeria. Akhmetzhanov et al, (2019) advocated the use of a massive prevention and control program to curtail the increasing prevalence of Lassa Fever in the region. NCDC (2020) states the following are generally supplied to areas at risk in Nigeria: medications and disinfectants (ribavirin injection, ribavirin tablet, medicine for supportive care, ringers lactate, metronidazole (flagyl), oral rehydration salts, personal protective and biosafety materials (boots, gloves), outer gown, plastic apron, mask, head cover, protective eyewear and bed nets sprayers, plastic sheets meant for mattress and barriers, kerosene lamp, body bags, buckets and containers, electric generator and laboratory supplies

\section{CONCLUSION}

Lassa fever outbreaks are known to occur during the dry season (November to April). The study established three statistically significant space-time clusters of Lassa fever cases in Owo town and its environs, which helped to show the pattern of spread of the disease within the city; It showed that the epidemics are in dry season. From at Iyere sub-urban area of the city through another peri-urban area at Ilale-Osijogun villages in 2019, epidemics of Lassa fever progressed until the largest outbreak, being a citywide epidemic occurred subsequently over a 5-month period November-March 2020. The Lassa fever epidemics in Owo town shows the classical pattern of a primary root of the epidemics being associated with Ehin-ogbe and Aruwajoye and their surrounding villages followed by community-level, person-to-person spread by contact. 
The study recommended that: In order to intervene in this epidemic in Owo, health promotion intervention should be directed to Ehin-ogbe and Aruwajoye and their surrounding villages. In order to further explore the results observed in this study, it is recommended that further studies with a larger sample size and more detailed analysis be conducted on the spatial distribution of Lassa fever virus across the South- in Nigeria. More information about the frequency of hostswitching and the degree of arena-virus and other pathogens circulation among rodents and humans is needed to better understand the implications of the assessment for the risk of Lassa fever and other rodent-borne disease outbreaks in Nigeria. It is, however, necessary to undertake a more spatial survey to further enhance our understanding of the distribution of these rodents for disease control purposes.

\section{REFERENCES}

Ajayi A.N, Chinedu, G.N, Ben, N.A., Benson, N.O., Elizabeth, U.N., Lawrence, U.O., Francis, I.O., Tobin, E., Stephan, G., \& Kingsley, N.U., (1995). Containing a Lassa fever epidemic in a resource-limited setting: outbreak description and lessons learned from Abakaliki, Nigeria (January-March 2012). Intl. J. Infect. Dis.17: e1011-e1016

Akhmetzhanov, A. R., Asai, Y., \& Nishiura, H. (2019). Quantifying the seasonal drivers of transmission for Lassa fever in Nigeria. Philosophical Transactions of the Royal Society $B, 374(1775), 20180268$.

Amorosa, V., MacNeil, A., McConnell, R., Patel, A., Dillon, K. E., Hamilton, K., ... \& Nichol, S. T. (2018). Imported lassa fever, Pennsylvania, USA, 2010. Emerging infectious diseases, 16(10), 1598.

Buchmeier, M. J., (2007). Arenavirus Z-glycoprotein association requires Z myristoylation but not functional RING or late domains. Journal of virology, 81(17), 9451-9460.

Carey,D.E.,Kemp,G.E.,White,H.A.,etal.,(2018). Lassa Fever Epidemiological Aspects Of The 1970 Epidemic,Jos,Nigeria.Trans.R.Soc.Trop.Med.Hyg.66,402408.doi:10.1016/0035-9203(72)90271-4.

Ehichioya DU, Hass M, O“lschlager S, Becker-Ziaja B, Chukwu CO, Coker J. (2020). Lassa fever, Nigeria, 2005-2008. Emerg. Infect. Dis.16:1040-1.

Federal Ministry of Health, (2016) Lassa Fever Outbreak in Nigeria. Abuja

Fisher-Hoch SP, Tomori O, Nasidi A, Perez-Oronoz GI, Fakile Y, Hutwagner L. (2017). Review of cases of nosocomial Lassa fever in Nigeria: the high price of poor medical practice.Brit. Med. J.311:857-9.

Frame, D. G., Demby, A. H., Coulibaly, M., Kanu, J., Goba, A., Bah, A., ... \& Rollin, P. E. (2017). Lassa fever in Guinea: I. Epidemiology of human disease and clinical observations. Vector borne and zoonotic diseases, 1(4), 269-281.

Ilori, E. A., Furuse, Y., Ipadeola, O. B., Dan-Nwafor, C. C., Abubakar, A., Womi-Eteng, O. E., ... \& Team, N. L. F. N. R. (2019). Epidemiologic and clinical features of Lassa fever outbreak in Nigeria, January 1-May 6, 2018. Emerging infectious diseases, 25(6), 1066.

Kish, L. (1965). Sampling organizations and groups of unequal sizes. American sociological review, 564-572.

Lawal, S. M (2018). Descriptive features of Lassa fever in Bauchi, Northeastern Nigeria-a retrospective review. Research Journal of Health Sciences, 6(3), 149-156. 
Monath, T.P., Meger, M., Casals, J., Kissling, R.E., Cacciapuoti, A. (2018). Lassa fever in the Eastern Province of Sierra Leone, 1970-1972. Clinical observations and virological studies on selected hospital cases. Am J. Trop. Med. Hyg. 23: 1140-1149

NigeriaCentreforDiseaseControl,2019.Diseasesituationreport:anupdateofLassafeveroutbreaki nNigeria.Availablefrom:https://www.ncdc.gov.ng/andhttps://www.ncdc.gov.ng/diseases /sitreps.

Ogbu, O. Ajuluchukwu, E., Uneke, C.J. (2017). Lassa fever in West African Sub-region: an Overview.J Vect Borne Dis. 44, pp. 1-11

OmilabuSA, Badaru SO, Okokhere P, Asogun D, DrostenC,Emmerich P(2015). Lassa fever, Nigeria, 2003 and 2004. Emerg. Infect. Dis.11:1642-4.

Reuben, C. R., \& Gyar, S. D. (2016). Knowledge, attitudes and practices of Lassa fever in and around Lafia, Central Nigeria. International Journal of Public Health and Epidemiology Research, 2(1), 014-019.

Salu, O. B., Amoo, O. S., Shaibu, J. O., Abejegah, C., Ayodeji, O., Musa, A. Z., ... \& Omilabu, S. A. (2020). Monitoring of Lassa virus infection in suspected and confirmed cases in Ondo State, Nigeria. The Pan African Medical Journal, 36.

Werner, D. (2004). Biological Resources and Migration. Springer, pp. 365.

WHO, (2020) Lassa Fever. Geneva, Switzerland

World Health Organization, (2015) Lassafever.Availablefrom:http://www.who.int/newsroom/fact-sheets/detail/lassa-feve

World Health Organization, (2018) Lassafever.Availablefrom:http://www.who.int/newsroom/fact-sheets/detail/lassa-feve

Yunusa, T., \& Egenti, N. (2015). Understanding Lassa fever virus and diversification of the Rodent vector in the tropics. Int J Curr Med Res, 4(6), 372-8. 